\title{
Frameshift mutations in coding repeats of protein tyrosine phosphatase genes in colorectal tumors with microsatellite instability

\author{
Sebastian Korff ${ }^{+1}$, Stefan M Woerner* ${ }^{* 1}$, Yan P Yuan², Peer Bork ${ }^{2,3}$, \\ Magnus von Knebel Doeberitz ${ }^{1}$ and Johannes Gebert ${ }^{1}$
}

Address: ${ }^{1}$ Department of Applied Tumor Biology, Institute of Pathology, University of Heidelberg, Heidelberg, Germany, ${ }^{2}$ European Molecular Biology Laboratory, Heidelberg, Germany and ${ }^{3}$ Max Delbrueck-Centrum for Molecular Medicine, Berlin, Germany

Email: Sebastian Korff - sebastian.korff@med.uni-heidelberg.de; Stefan M Woerner* - stefan.woerner@med.uni-heidelberg.de; Yan P Yuan - yanping.yuan@embl-heidelberg.de; Peer Bork - peer.bork@embl-heidelberg.de; Magnus von Knebel Doeberitz - knebel@med.uniheidelberg.de; Johannes Gebert - johannes.gebert@med.uni-heidelberg.de

* Corresponding author †Equal contributors

Published: 10 November 2008

BMC Cancer 2008, 8:329 doi:10.1 186/147|-2407-8-329
Received: 20 November 2007

Accepted: 10 November 2008

This article is available from: http://www.biomedcentral.com/I47I-2407/8/329

(c) 2008 Korff et al; licensee BioMed Central Ltd.

This is an Open Access article distributed under the terms of the Creative Commons Attribution License (http://creativecommons.org/licenses/by/2.0), which permits unrestricted use, distribution, and reproduction in any medium, provided the original work is properly cited.

\begin{abstract}
Background: Protein tyrosine phosphatases (PTPs) like their antagonizing protein tyrosine kinases are key regulators of signal transduction thereby assuring normal control of cellular growth and differentiation. Increasing evidence suggests that mutations in PTP genes are associated with human malignancies. For example, mutational analysis of the tyrosine phosphatase (PTP) gene superfamily uncovered genetic alterations in about $26 \%$ of colorectal tumors. Since in these studies tumors have not been stratified according to genetic instability status we hypothesized that colorectal tumors characterized by high-level of microsatellite instability (MSI-H) might show an increased frequency of frameshift mutations in those PTP genes that harbor long mononucleotide repeats in their coding region (cMNR).

Results: Using bioinformatic analysis we identified 16 PTP candidate genes with long cMNRs that were examined for genetic alterations in $19 \mathrm{MSI}-\mathrm{H}$ colon cell lines, $54 \mathrm{MSI}-\mathrm{H}$ colorectal cancers, and $17 \mathrm{MSI}-\mathrm{H}$ colorectal adenomas. Frameshift mutations were identified only in 6 PTP genes, of which PTPN2I show the highest mutation frequency at all in MSI-H tumors (17\%).

Conclusion: Although about $32 \%$ of MSI-H tumors showed at least one affected PTP gene, and cMNR mutation rates in PTPN2 I, PTPRS, and PTPN5 are higher than the mean mutation frequency of MNRs of the same length, mutations within PTP genes do not seem to play a common role in MSI tumorigenesis, since no CMNR mutation frequency reached statistical significance and therefore, failed prediction as a Positive Selective Target Gene.
\end{abstract}

\section{Background}

Chromosomal instability (CIN) and aneuploidy are molecular features of most sporadic colorectal cancers $(\sim 85 \%)$ and may confer a worse prognosis [1-3]. About
$15 \%$ of colorectal cancers (CRC) show microsatellite instability (MSI) due to defective DNA mismatch repair (MMR; [4]). In hereditary non-polyposis colorectal cancer (HNPCC/Lynch syndrome; about 5\% of all CRC cases) 
most of the tumors display this MSI phenotype [5]. As a common molecular theme, MMR-deficient MSI tumors of the colon and other organs accumulate numerous insertion/deletion mutations [6,7] not only at non-coding but also at coding microsatellites (cMS) that cause translational frameshifts and abrogate normal protein function. Such frameshift protein derived neo-peptides can be highly immunogenic and are capable to induce cytotoxic T-cell-mediated killing of MSI-H tumor cells in vitro [811]. Frameshift mutations in cMS sequences of a large number of candidate genes have been identified [12-16] and mutations in some of them (TGFBR2, ACVR2, BAX; TCF-4) appear to provide a growth advantage to affected cells [17-20]. Both, sporadic and HNPCC-associated colorectal MSI-H cancers, show distinct clinico-pathological characteristics that include frequent proximal site, diploidy, poor differentiation, less distant metastases, peritumoral lymphocytic infiltrate, comparably good prognosis, and altered chemoresponsiveness [6,7,21-26]. Increasing evidence suggests that cMS mutations in a limited number of target genes appear to be selected for during MSI carcinogenesis and might account for some of these clinico-histopathological features.

Protein tyrosine phosphatases (PTPs) like their antagonizing protein tyrosine kinases are key regulators of signal transduction thereby assuring normal control of cellular growth and differentiation [27]. Alterations in the delicate balance between tyrosine phosphorylation and dephosphorylation contribute to the pathogenesis of different inherited or acquired human diseases including autoimmunity, diabetes, and cancer [27-29]. Several studies indicate that mutations in PTP genes may be involved in colorectal carcinogenesis. For example, increased PTPRA mRNA levels have been observed in late stage colorectal tumors [30] and frequent overexpression of the human transmembrane-type PTP SAP-1 may occur relatively late in the adenoma-carcinoma sequence [31]. Expression profiling studies also suggested that PTPs appear to be involved in metastasis of colorectal cancer [32]. In a similar approach, differential expression of the human PTPN21 gene was observed when comparing MSI-H with microsatellite stable (MSS) colorectal cancer cell lines [33] and mutations in this gene were reported to occur in a subset of MSI-H colorectal carcinomas [34]. Additionally, a somatic mutation in the non-receptor PTP Shp2, encoded by the PTPN11 gene, has been detected in a single colon tumor with an increased frequency of somatic alterations, but without microsatellite instability [35]. Moreover, identification of the murine PTP gene Ptprj as a modifier locus conferring susceptibility to colorectal cancer also led to the detection of frequent deletions of the human PTPRJ gene in primary colon cancers [36]. Finally, systematic mutational analysis of the human PTP gene super family identified somatic mutations in six
PTPs (PTPRF, PTPRG, PTPRT, PTPN3, PTPN13, PTPN14), affecting $26 \%$ of colorectal cancers [37].

However, whether coding mononucleotide repeats (cMNR) in PTP genes are specific targets of frameshift mutations in MMR-deficient colorectal tumors is still unknown. In the present study we identified 16 human PTP genes harboring coding region microsatellites and determined their mutation frequencies in MSI-H colorectal tumors. About $32 \%$ of MSI-H tumors showed frameshift mutations in any of these PTP genes. However, gene-specific cMNR mutation frequencies did not reach statistical significance according to our recently proposed model for Selective Target Gene prediction [16]. Hence, there is no significant statistical support for a common involvement of any of these PTP genes in MSI colon carcinogenesis.

\section{Methods \\ Cell Lines and Tumor Tissues}

Most of the cell lines analyzed in the present study have been described previously [15]. Additional human colorectal cancer cell lines were obtained from Cell Line Services (CLS), Heidelberg, Germany (Colo94H, Colo205, HCT8, SW1116, SW403, T84) or kindly provided by Dr. M. Brattain, University of Texas, Health Science Center, San Antonio, TX (CBS, FET), Dr. J. Wilson, Case Western Reserve University, Cleveland, Ohio (Vaco5, Vaco6, Vaco432, Vaco457), or Dr. I. Fidler (KM12). Cells were grown in RPMI supplemented with $10 \%$ fetal calf serum (Life Technologies, Karlsruhe, Germany). Formalin-fixed and Paraffin-embedded tumor and matched normal mucosae samples were treated as described [38]. The MSI status of tumor cell lines (19 MSI-H, 17 MSS), primary colorectal tumors (54 MSI-H and matched normal mucosae), and colorectal adenomas (17 MSI-H, 6 MSS, and matched normal mucosae) has been determined using the NCI/ICG-HNPCC microsatellite marker panel [39] as previously described [38]. Whole blood DNA samples of 60 healthy donors served as additional MSS controls. Informed consent was obtained from all patients and blood donors.

\section{Candidate cMNR Sequences in PTP Genes}

Human PTP genes were sought in our cMNR database ([15] accessible at http://www.seltarbase.org, MNR_ensembl) that covers all human candidate coding mononucleotide repeats in the entire human genome annotated in the Ensembl database (Ensembl 19.34b, 2004). Candidate cMNRs with repeat length of at least 7 repeat units were considered for further analysis.

\section{cMNR Instability Analysis}

Primer design, DNA fragment and data analysis was performed as described [40]. Primer sequences and anneal- 
ing temperatures are shown in Table 1 [see Additional file 1]. Frameshift mutations were verified by DNA sequence analysis.

\section{Results}

cMNR instability of PTPs in MSI-H colorectal cancer cell lines

A candidate set of 16 PTP genes that contained cMNR sequences composed of at least 7 repeat units were retrieved from our cMNR database (Table 1 [see Additional file 1], MNR_ensembl is accessible at http:// www.seltarbase.org). Using DNA fragment analysis we examined cMNR length alterations of these candidate genes in 19 MSI-H and 17 MSS colorectal cancer cell lines. cMNR frameshift mutations occurred exclusively in MSI$\mathrm{H}$ colorectal cancer cell lines and affected four PTP genes (Tables 2 and 4 [see Additional file 1]; PTPN21, PTPN13,
PTPRS, PTPN23). Results of fragment analysis are exemplarily shown in figure 1 . The highest mutation frequencies were associated with the $\mathrm{A}_{8}$ cMNRs in PTPN13 (22\%) and PTPN21 (26\%). All mutations occurred in a heterozygous state and predominantly represented single nucleotide deletions (minus 1 allele, $\mathrm{n}=10$ ). Two were single nucleotide insertions (plus 1 allele, PTPN13 and PTPN21). No larger shifts could be detected. Overall, the larger fraction of MSI-H colorectal cancer cell lines (63\%; $12 / 19)$ showed frameshift mutations in any of the four affected PTP genes.

\section{PTP cMNR Mutations in MSI-H Primary Colorectal Carcinomas}

We next analyzed the same set of 16 PTP genes for cMNR frameshift mutations in $54 \mathrm{MSI}-\mathrm{H}$ colorectal carcinomas and adjacent normal mucosa. Frameshift mutations in

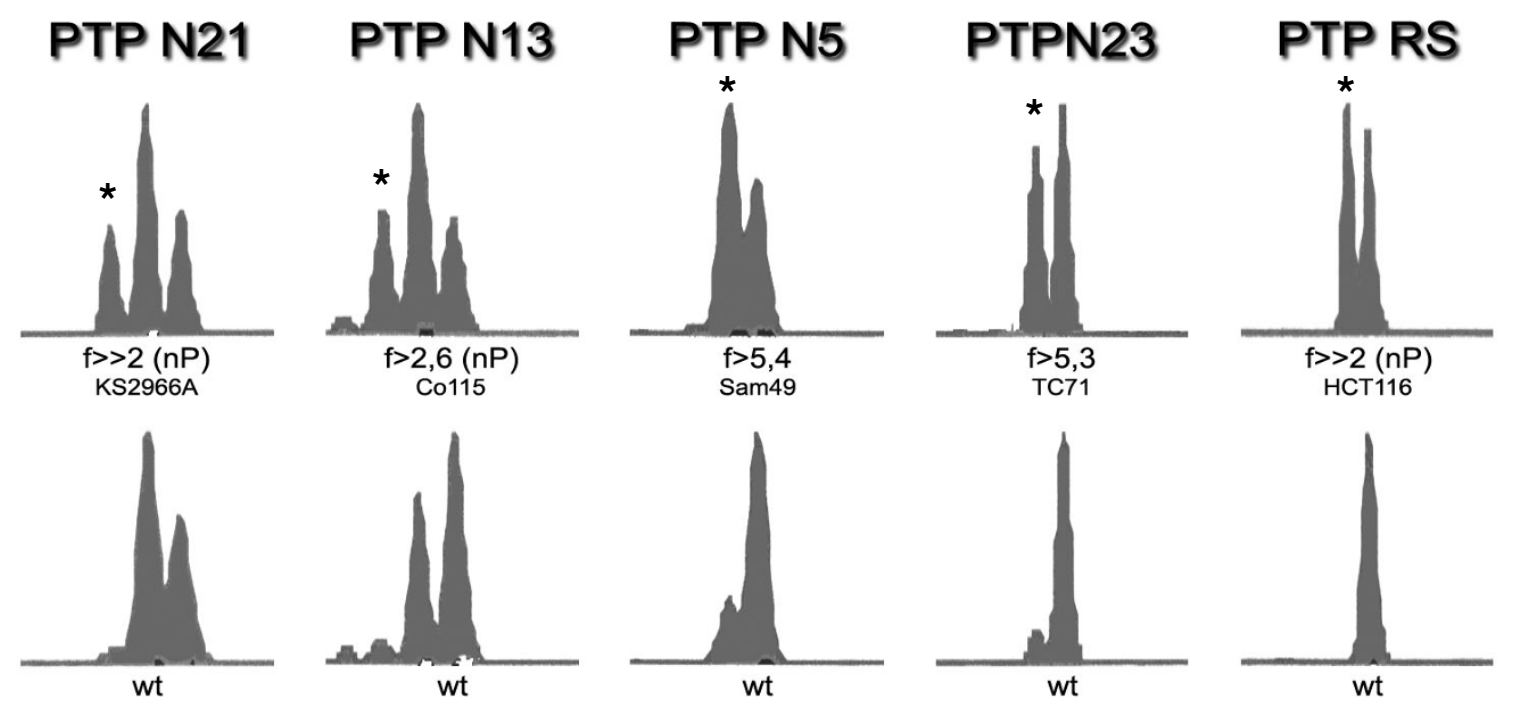

\section{Figure I}

Electropherograms of allelic shifts. Electropherograms of shifted alleles. DNA fragment analysis of a representative set of PTP cMNRs in a MSI-H colorectal tumor (KS2966A, Sam49) and MSI-H cancer cell lines (Col I5, TC7I, and HCTI I6). Corresponding wildtype alleles (wt, lower panel) are indicated together with tumor cell-specific allelic shifts marked by asterisks (upper panel). Allele intensities were determined (peak area) and ratios ( $f$ ) of wildtype and novel alleles in primary tumors and cell lines were calculated, defining a 2-fold difference as threshold for allelic shifts. 
these primary tumors were identified in 6 PTP genes (PTPN21, PTPRS, PTPN5, PTPN23, PTPRA, PTPRE) comprising mutation targets shared by (PTPN21, PTPRS, PTPN23) or different from (PTPN5, PTPRA, PTPRE) those in the MSI-H cell lines (Tables 3 and 4 [see Additional file 1], Figure 1). In MSS mucosa samples such changes almost never occurred (1/703 analyses). Two genes, PTPN21 and PTPRS, were most frequently affected in primary colorectal tumors (16\% and $12 \%$, respectively). However, primary tumors lacked frameshift mutations in the $\mathrm{A}_{8}$ repeat of PTPN13 and thus appeared to arise only in cultured MSI-H CRC cell lines. Since LS174T and LS180 are derived from the same primary tumor [41,42] and the overall mutation frequency is quite low it is very likely that this mutation already manifested within the primary tumor. Vice versa, mutations in three other PTPs (PTPN5, PTPRA, PTPRE) remained restricted to primary tumors and occurred at very low frequency (Tables 3 and 4 [see Additional file 1]). Overall, frameshift mutations in any of these 6 PTP genes were observed in 32\% of MSI-H tumors. The most common type of mutation were single nucleotide deletions $(16 / 21,76 \%)$ and all frameshift mutations appeared to affect only one allele (heterozygous). Interestingly, all PTP mutations are located within or upstream of the phosphatase domains and hence are expected to impair or completely abrogate phosphatase activity (Figure 2).

PTPN2 I cMNR Mutations in MSI-H Colorectal Adenomas Since mutations in the $A_{8}$ coding repeat of PTPN21 were the most frequent genetic alterations shared by MSI-H cancer cell lines and primary tumors we also analyzed this coding repeat in $17 \mathrm{MSI}-\mathrm{H}$ and $6 \mathrm{MSS}$ colorectal adenoma samples. As expected, no cMNR frameshift mutations
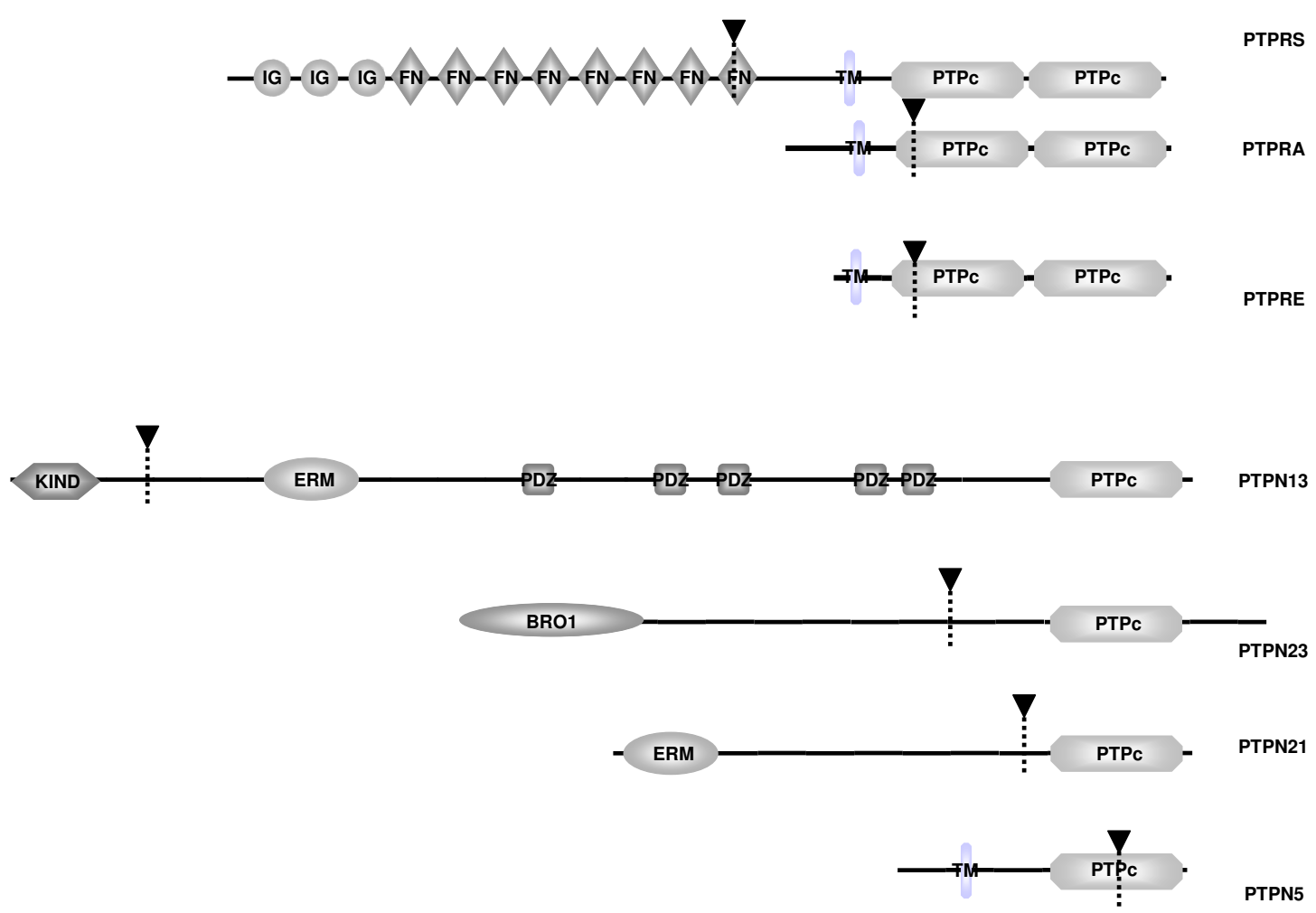

\section{Figure 2}

Domain structure of selected PTPs and sites of cMNR frameshift mutations. Structure of PTP proteins. Tyrosine phosphatase domains (PTPc) as well as frameshift mutation sites (arrowhead, stippled lines) are indicated. Remaining domain abbreviations: IG immunoglobulin like domain, FN fibronectin type 3 domain, KIND kinase non-catalytic C-lobe domain, ERM ezrin/radixin/moesin domain, PDZ Domain present in PSD-95, Dlg, and ZO-I/2., BROI BROI-like domain, TM transmembrane domain. Despite PTPN5 is a non-receptor phosphatase there is a TM domain annotated within Ensembl. 
were detected in the MSS adenomas. However, in 2 of 17 MSI-H adenomas we identified deletion and insertion mutations (Table 4 [see Additional file 1], Figure 1). These results rather argue for an early event during MSI colorectal carcinogenesis.

\section{Discussion}

The goal of this study was to determine type, frequency, and pattern of $\mathrm{cMNR}$ frameshift mutations in protein PTP genes in MSI-H colorectal cancer cell lines and primary colon tumors. This gene family was selected because PTPs are expected to exert tumor suppressive function and thus represent potential targets of inactivating mutations in DNA mismatch repair deficient tumors. Among the large number of PTP genes in the human genome we selected 16 PTP genes that contained coding region microsatellites of increased length ( $\geq 7$ repetitive units). Our results provide evidence for frameshift mutations in six of these PTP genes (PTPN21, PTPRS, PTPN5, PTPN23, PTPRA, PTPRE) affecting about $32 \%$ of MSI-H colorectal cancers. This frequency differs slightly from a previous study that reported PTP mutations in $26 \%$ of unselected colorectal carcinomas [37]. Although most of the coding repeat-harboring PTP genes (13/16 candidates) analyzed by us have also been examined by Wang and co-workers, different sets of mutated PTP genes were identified in both studies. In particular, we observed tumor-specific genetic alterations in PTPN21, PTPN23, PTPN5, PTPRA, PTPRE and PTPRS whereas mutations reported by Wang et al. were confined to PTPRF, PTPRG, PTPRT, PTPN3, PTPN13, and PTPN14. This difference most probably can be explained by the different screening strategies used in these two studies. Wang et al. performed their initial mutational pre-screening on a set of 18 unselected colorectal tumors, This subset would be expected to include only 2 to 3 MSI tumors based on a general MSI frequency of 15\% reported for unselected colorectal cancers. Since the type of mutation and the spectrum of affected genes is remarkably different among MSS and MSI-H tumors, the observed differences are not unexpected. However, there were also some consistent findings in both studies. For example, PTPN13 was examined by both groups but no cMNR mutations were observed in a cumulative number of 69 MSI-H CRC samples ([43] and data presented here). Interestingly, Wang et al. described two nonsense or frameshift mutations at the expected MNR position within PTPN13. Unfortunately, any information about the MSI status of these tumors is missing. So, our investigation represent a reasonable completion of a systematic analysis of human PTP genes in human colorectal cancers.

Recently, we proposed a statistical model that allows to predict positively or negatively selected target genes of MSI tumorigenesis in an organ-specific manner based on cMNR mutation frequencies [16]. According to the actual release of this model (http://www.seltarbase.org, release 200711), cMNRs of 7 or 8 repetitive units - in the absence of any biological selection pressure - are expected to show a mean somatic mutation rate of about $4 \%$ and $9 \%$ respectively. In order to qualify as positively selected MSI target genes, tumor-specific mutation frequencies for cMNRs of this length have to exceed $22 \%$ and $28 \%$, respectively. The three most frequently mutated PTPs identified in the present study (PTPN21 [A 8 , PTPRS $\left[\mathrm{C}_{7}\right]$, PTPN5 $\left[\mathrm{C}_{7}\right]$ ) show mutation frequencies of $17 \%, 12 \%$, and $6 \%$, respectively. The final overall mutation frequency of PTPN21 $\mathrm{A}_{8}(14.4 \%)$ is even slightly lower, when considering data from the literature [14]. Certainly, we did not extend our mutation search to the entire coding sequence of each PTP gene, and therefore, additional mutations outside the cMNR sequence cannot be excluded. Furthermore, detailed studies of individual tumor types have provided compelling evidence that mutations of different genes but within the same pathway can have similar functional effects, i.e. leading to its disruption and providing a growth advantage to affected cells [37], as it has been proposed for apoptotic genes like Fas, Apaf-1, and $B c l-10$ [44]. In conclusion, although these gene-specific mutation rates are higher than the mean mutation frequencies for this length of repeats they do not reach statistical significance and prediction about positive Selective Target Genes in MSI-H tumorigenesis is not feasible. Therefore, human PTP genes do not seem to play a common role in MSI-H tumorigenesis. However, contribution to individual tumor development cannot be excluded. Furthermore, the observation of 2 mutations within a set of $17 \mathrm{MSI}-\mathrm{H}$ adenomas in PTPN21 argues for an early event in malignant transformation.

Despite some structural diversity, the six PTP proteins found to be mutated in the present study share a catalytically active phosphatase that resides in one (PTPN21, PTPN23, PTPN5, PTPRS) or two (PTPRA) C-terminal domains [45]. Notably, all cMNR frameshift mutation sites are located upstream or within the first half of these catalytic domains (see Figure 2) resulting in truncated proteins that are expected to show partial or complete loss of phosphatase activity. However, all PTP frameshift mutations only affected a single allele leaving the cMNR on the remaining allele intact. The presence of contaminating normal inflammatory cells in these tumors may well account for this observation. Alternatively, the remaining wildtype copy may be silenced by epigenetic mechanisms. The absence of biallelic mutations in the analyzed tumors could be due to a dominant negative fashion or affection of gene dosage [46,47]. Shortened transcripts of murine PTPs lacking catalytic or interaction domains by alternative splicing can act in a dominant negative manner [48]. 
From our analysis of preneoplastic lesions we further conclude that PTPN21 frameshift mutations also occur in MSI-H colorectal adenomas albeit at lower frequency $(12 \%)$ thereby indicating an early step during MSI tumorigenesis. At the protein level, PTPN21 is known to bind to and activate c-Src and Etk protein kinases [49,50]. Interestingly, activated Etk has been reported to trigger apoptosis in breast cancer cells via Stat1 and p21 [51]. By analogy, we hypothesize that inactivation of PTPN21 by cMNR frameshift mutations in MSI-H colon cancer cells might lead to Etk inactivation and subsequent inhibition of apoptosis.

\section{Conclusion}

The work presented here shows a systematic investigation using an evidence based approach: cMNRs of human PTP genes with the highest chance for mutational events in MSI-H colorectal tumors were selected. Although we observed a similar overall mutation frequency in MSI colorectal cancers compared to the results reported by Wang et al. for unselected colorectal cancers, a different set of PTP genes appears to be mutated in MSI tumors. Human PTP genes identified in the present study seem to play no common role in the tumorigenesis of MSI-H tumors, supported by statistical considerations. However, within individual MSI-H carcinogenesis such mutations could have had impact to malignant transformation, but so far no functional data exist that could confirm this hypothesis.

\section{Competing interests}

The authors declare that they have no competing interests.

\section{Authors' contributions}

SK carried out the molecular analyses, participated in the data analysis and interpretation, and drafted the manuscript, SMW participated in the design of the study, in the data analysis and interpretation, performed the statistical analysis, and contributed to manuscript writing, YPY and PB did the bioinformatic analysis and established the human CMNR database and the list of candidate genes, MvKD provided project supervision, JG provided the general concept, design of study, supervision and contributed to manuscript writing.

All authors read and approved the final manuscript.

\section{Note}

Table 1: Coding microsatellites in candidate PTP genes examined in this study.

For each of the 16 PTPs is given the official HUGO identification (hugoID), the actual Ensembl entry ID at http:// www.ensembl.org/Homo_sapiens (ENSG), the chromosomal localization (Chr.), the former EMBL accession number (Acc. no.), the type of tract (nucleotide and length, cMNR), the exact position of the tract in relation to the sequence of the EMBL entry (Pos.), the annealing temperature for PCR (Ta) as well as the primer sequences ( $5^{\prime}->3^{\prime}$, sense and antisense) used for fragment analysis of the respective tract.

Table 2: Allelic cMNR mutation status in MSI-H colorectal cancer cell lines.

Wild type: wt; Deletions of one or two mononucleotides: $-1,-2$; Insertions of one or two mononucleotides: $+1,+2$; Analysis failed or not evaluable: 0 .

Table 3: Allelic cMNR mutation status in MSI-H colorectal carcinomas.

For abbreviations see legend of Table 2.

Table 4: PTP cMNR mutation frequencies in MSI-H colorectal cancer cell lines, tumors, and adenomas*.

*Analysis restricted to PTPN21.

\section{Additional material}

\section{Additional file 1}

Supplemental material and results information. Table 1 shows the PTP candidate list including primer systems used for the fragment analysis, Tables 2 and 3 present cMNR mutation status information in MSI-H colorectal cancer cell lines and tumors, and Table 4 summarizes the mutation frequencies of the PTP candidate genes in MSI-H colorectal cancer cell lines, tumors, and adenomas.

Click here for file

[http://www.biomedcentral.com/content/supplementary/14712407-8-329-S1.doc]

\section{Acknowledgements}

We gratefully acknowledge the excellent technical assistance of B. Kuchenbuch and G. Russell. This work was supported by the Deutsche Krebshilfe (M.v.K.D.; J.G.), DFG and BMBF (P.B.).

\section{References}

I. Remvikos $Y$, Tominaga O, Hammel P, Laurent-Puig P, Salmon RJ, Dutrillaux B, et al.: Increased p53 protein content of colorectal tumours correlates with poor survival. $\mathrm{Br} J$ Cancer 1992, 66:758-764.

2. Jen J, Kim H, Piantadosi S, Liu ZF, Levitt RC, Sistonen P, et al.: Allelic loss of chromosome $18 \mathrm{q}$ and prognosis in colorectal cancer. N Engl J Med 1994, 331:213-221.

3. Laurent-Puig P, Olschwang S, Delattre O, Remvikos $Y$, Asselain B, Melot T, et al:: Survival and acquired genetic alterations in colorectal cancer. Gastroenterology 1992, 102: I |36-I I4|

4. Imai $\mathrm{K}$, Yamamoto $\mathrm{H}$ : Carcinogenesis and microsatellite instability: the interrelationship between genetics and epigenetics. Carcinogenesis 2008, 29:673-680.

5. Lynch HT, Lynch JF, Lynch PM, Attard T: Hereditary colorectal cancer syndromes: molecular genetics, genetic counseling, diagnosis and management. Fam Cancer 2008, 7:27-39. 
6. Ionov $\mathrm{Y}$, Peinado MA, Malkhosyan S, Shibata D, Perucho M: Ubiquitous somatic mutations in simple repeated sequences revea a new mechanism for colonic carcinogenesis. Nature 1993 363:558-56I.

7. Thibodeau SN, Bren G, Schaid D: Microsatellite instability in cancer of the proximal colon. Science 1993, 260:816-819.

8. Linnebacher M, Gebert J, Rudy W, Woerner S, Yuan YP, Bork P, et al.: Frameshift peptide-derived $T$-cell epitopes: a source of novel tumor-specific antigens. Int J Cancer 200I, 93:6-II.

9. Saeterdal I, Bjorheim J, Lislerud K, Gjertsen MK, Bukholm IK, Olsen $\mathrm{OC}$, et al:: Frameshift-mutation-derived peptides as tumorspecific antigens in inherited and spontaneous colorectal cancer. Proc Natl Acad Sci USA 200I, 98: |3255-I3260.

10. Ripberger E, Linnebacher M, Schwitalle Y, Gebert J, von Knebel Doeberitz M: Identification of an HLA-A020I-restricted CTL epitope generated by a tumor-specific frameshift mutation in a coding microsatellite of the OGT gene. J Clin Immunol 2003, 23:415-423.

II. Schwitalle Y, Linnebacher M, Ripberger E, Gebert J, von Knebel Doeberitz $M$ : Immunogenic peptides generated by frameshift mutations in DNA mismatch repair-deficient cancer cells. Cancer Immun 2004, 4: I4.

12. Duval A, lacopetta B, Ranzani GN, Lothe RA, Thomas G, Hamelin R: Variable mutation frequencies in coding repeats of TCF-4 and other target genes in colon, gastric and endometrial carcinoma showing microsatellite instability. Oncogene 1999 , I 8:6806-6809.

13. Kim NG, Rhee H, Li LS, Kim H, Lee JS, Kim JH, et al.: Identification of MARCKS, FLJII383 and TAFIB as putative novel target genes in colorectal carcinomas with microsatellite instability. Oncogene 2002, $21: 5081-5087$

14. Mori Y, Yin J, Rashid A, Leggett BA, Young J, Simms L, et al.: Instabilotyping: comprehensive identification of frameshift mutations caused by coding region microsatellite instability. Cancer Res 2001, 6 I:6046-6049.

15. Woerner SM, Gebert J, Yuan YP, Sutter C, Ridder R, Bork P, et al.: Systematic identification of genes with coding microsatellites mutated in DNA mismatch repair-deficient cancer cells. Int J Cancer 200I, 93:I2-19.

16. Woerner SM, Benner A, Sutter C, Schiller M, Yuan YP, Keller G, et al.: Pathogenesis of DNA repair-deficient cancers: a statistical meta-analysis of putative Real Common Target genes. Oncogene 2003, 22:2226-2235.

17. Grady WM, Rajput A, Myeroff L, Liu DF, Kwon K, Willis J, et al.: Mutation of the type II transforming growth factor-beta receptor is coincident with the transformation of human colon adenomas to malignant carcinomas. Cancer Res 1998, 58:310I-3I04.

18. Hempen PM, Zhang L, Bansal RK, lacobuzio-Donahue CA, Murphy KM, Maitra A, et al.: Evidence of Selection for Clones Having Genetic Inactivation of the Activin A Type II Receptor (ACVR2) Gene in Gastrointestinal Cancers. Cancer Res 2003, 63:994-999.

19. Ionov Y, Yamamoto H, Krajewski S, Reed JC, Perucho M: Mutational inactivation of the proapoptotic gene $B A X$ confers selective advantage during tumor clonal evolution. Proc Natl Acad Sci USA 2000, 97:10872-10877.

20. Cuilliere-Dartigues P, El-Bchiri J, Krimi A, Buhard O, Fontanges P, Flejou JF, et al.: TCF-4 isoforms absent in TCF-4 mutated MSI-H colorectal cancer cells colocalize with nuclear CtBP and repress TCF-4-mediated transcription. Oncogene 2006, 25:444I-4448.

21. Buckowitz A, Knaebel HP, Benner A, Blaker H, Gebert J, Kienle P, et al:: Microsatellite instability in colorectal cancer is associated with local lymphocyte infiltration and low frequency of distant metastases. BrJ Cancer 2005, 92: I746-I753.

22. Smyrk TC, Watson P, Kaul K, Lynch HT: Tumor-infiltrating lymphocytes are a marker for microsatellite instability in colorectal carcinoma. Cancer 2001, 91:2417-2422.

23. Gryfe R, Kim H, Hsieh ET, Aronson MD, Holowaty EJ, Bull SB, et al:: Tumor microsatellite instability and clinical outcome in young patients with colorectal cancer. N Engl J Med 2000, 342:69-77.

24. Samowitz WS, Holden JA, Curtin K, Edwards SL, Walker AR, Lin HA, et al.: Inverse relationship between microsatellite instability and K-ras and p53 gene alterations in colon cancer. Am J Pathol 200I, I58:1517-I524.

25. Carethers JM, Smith EJ, Behling CA, Nguyen L, Tajima A, Doctolero $\mathrm{RT}$, et al.: Use of $\mathbf{5}$-fluorouracil and survival in patients with microsatellite-unstable colorectal cancer. Gastroenterology 2004, I 26:394-401.

26. Ribic CM, Sargent DJ, Moore MJ, Thibodeau SN, French AJ, Goldberg $\mathrm{RM}$, et al.: Tumor microsatellite-instability status as a predictor of benefit from fluorouracil-based adjuvant chemotherapy for colon cancer. N Engl J Med 2003, 349:247-257.

27. Tonks NK, Neel BG: Combinatorial control of the specificity of protein tyrosine phosphatases. Curr Opin Cell Biol 200I, I3:182-195.

28. Blume-Jensen $\mathrm{P}$, Hunter T: Oncogenic kinase signalling. Nature 200I, 4I I:355-365.

29. Yu CC, Mamchak AA, DeFranco AL: Signaling mutations and autoimmunity. Curr Dir Autoimmun 2003, 6:6 I-88.

30. Tabiti K, Smith DR, Goh HS, Pallen C): Increased mRNA expression of the receptor-like protein tyrosine phosphatase alpha in late stage colon carcinomas. Cancer Lett 1995, 93:239-248.

31. Seo Y, Matozaki T, Tsuda M, Hayashi Y, Itoh H, Kasuga M: Overexpression of SAP-I, a transmembrane-type protein tyrosine phosphatase, in human colorectal cancers. Biochem Biophys Res Commun 1997, 23 I:705-7II.

32. Saha S, Bardelli A, Buckhaults P, Velculescu VE, Rago C, St CB, et al.: A phosphatase associated with metastasis of colorectal cancer. Science 2001, 294: I343-1346.

33. Dunican DS, McWilliam P, Tighe O, Parle-McDermott A, Croke DT: Gene expression differences between the microsatellite instability (MIN) and chromosomal instability (CIN) phenotypes in colorectal cancer revealed by high-density cDNA array hybridization. Oncogene 2002, 21 :3253-3257

34. Mori Y, Sato F, Selaru FM, Olaru A, Perry K, Kimos MC, et al.: Instabilotyping reveals unique mutational spectra in microsatellite-unstable gastric cancers. Cancer Res 2002, 62:364I-3645.

35. Bentires-Alj M, Paez JG, David FS, Keilhack H, Halmos B, Naoki K, et al.: Activating mutations of the noonan syndrome-associated SHP2/PTPNII gene in human solid tumors and adult acute myelogenous leukemia. Cancer Res 2004, 64:8816-8820.

36. Ruivenkamp CA, van WT, Zanon C, Stassen AP, Vlcek C, Csikos T, et al: Ptprj is a candidate for the mouse colon-cancer susceptibility locus Sccl and is frequently deleted in human cancers. Nat Genet 2002, 3 I:295-300.

37. Wang Z, Shen D, Parsons DW, Bardelli A, Sager J, Szabo S, et al.: Mutational analysis of the tyrosine phosphatome in colorectal cancers. Science 2004, 304: I | 64- I I 66

38. Sutter C, Gebert J, Bischoff P, Herfarth C, von Knebel Doeberitz M: Molecular screening of potential HNPCC patients using a multiplex microsatellite PCR system. Mol Cell Probes 1999, I3:157-165

39. Boland CR, Thibodeau SN, Hamilton SR, Sidransky D, Eshleman JR, Burt RW, et al.: A National Cancer Institute Workshop on Microsatellite Instability for cancer detection and familial predisposition: development of international criteria for the determination of microsatellite instability in colorectal cancer. Cancer Res 1998, 58:5248-5257.

40. Woerner SM, Kloor M, Mueller A, Rueschoff J, Friedrichs N, Buettner $\mathrm{R}$, et al.: Microsatellite instability of selective target genes in HNPCC-associated colon adenomas. Oncogene 2005, 24:2525-2535.

4I. Tom BH, Rutzky LP, Jakstys MM, Oyasu R, Kaye Cl, Kahan BD: Human colonic adenocarcinoma cells. I. Establishment and description of a new line. In Vitro 1976, I2:180-191.

42. Tom BH, Rutzky LP, Oyasu R, Tomita JT, Goldenberg DM, Kahan BD: Human colon adenocarcinoma cells. II. Tumorigenic and organoid expression in vivo and in vitro. J Natl Cancer Inst 1977 , 58: $1507-1512$.

43. Vilkki S, Launonen V, Karhu A, Sistonen P, Vastrik I, Aaltonen LA Screening for microsatellite instability target genes in colorectal cancers. J Med Genet 2002, 39:785-789.

44. Yamamoto H, Gil J, Schwartz S Jr, Perucho M: Frameshift mutations in Fas, Apaf-I, and Bcl- 10 in gastro-intestinal cancer of the microsatellite mutator phenotype. Cell Death Differ 2000, 7:238-239.

45. Tonks NK: Protein tyrosine phosphatases: from genes, to function, to disease. Nat Rev Mol Cell Biol 2006, 7:833-846. 
46. Fodde R, Smits R: Cancer biology. A matter of dosage. Science 2002, 298:76I-763.

47. Santarosa M, Ashworth A: Haploinsufficiency for tumour suppressor genes: when you don't need to go all the way. Biochim Biophys Acta 2004, 1654:105-122.

48. Forrest AR, Taylor DF, Crowe ML, Chalk AM, Waddell NJ, Kolle G, et al: Genome-wide review of transcriptional complexity in mouse protein kinases and phosphatases. Genome Biol 2006, 7:R5.

49. Jui HY, Tseng RJ, Wen X, Fang HI, Huang LM, Chen KY, et al:: Protein-tyrosine phosphatase $\mathrm{DI}$, a potential regulator and effector for Tec family kinases. I Biol Chem 2000, 275:4II24-4III32

50. Cardone L, Carlucci A, Affaitati A, Livigni A, DeCristofaro T, Garbi C, et al:: Mitochondrial AKAP I 2 I binds and targets protein tyrosine phosphatase DI, a novel positive regulator of src signaling. Mol Cell Biol 2004, 24:46I 3-4626.

5I. Yao H, Song E, Chen J, Hamar P: Expression of FAP-I by human colon adenocarcinoma: implication for resistance against Fas-mediated apoptosis in cancer. $\mathrm{Br} J$ Cancer 2004, 91:17|8-1725.

\section{Pre-publication history}

The pre-publication history for this paper can be accessed here:

http://www.biomedcentral.com/1471-2407/8/329/pre pub

Publish with Biomed Central and every scientist can read your work free of charge

"BioMed Central will be the most significant development for disseminating the results of biomedical research in our lifetime. "

Sir Paul Nurse, Cancer Research UK

Your research papers will be:

- available free of charge to the entire biomedical community

- peer reviewed and published immediately upon acceptance

- cited in PubMed and archived on PubMed Central

- yours - you keep the copyright

Submit your manuscript here:

http://www.biomedcentral.com/info/publishing_adv.asp 